\title{
A History of Nuclear Cardiology in the UK
}

\author{
S. Richard Underwood
}

\subsection{Historical Perspective}

The potential of radionuclides as tracers for the investigation of the circulation was realised many years ago but early experiments were hampered by primitive equipment. Blumgart and colleagues reported the first use of a radionuclide tracer in man in 1927. They used a cloud chamber to measure the transit time of intravenous radium $\mathrm{C}$ from one arm to the other and they noted much longer circulation times in patients with heart failure. In the late 1940s Prinzmetal and colleagues established the use of precordial time-activity curves following intravenous injection of a bolus of radionuclide. They used sodium-24 and a Geiger-Müller tube, but the technique was developed using iodine-131 and a more reliable scintillation counter by Shipley and colleagues, and was used by Huff and colleagues in conjunction with the Hamilton equation to measure cardiac output.

The first cardiac images were produced using a rectilinear scanner but further advances were made with the development of more suitable radioactive tracers and more sophisticated imaging equipment. In 1957 Anger's invention of the gamma camera opened the door for rapid development, initially with blood pool imaging, progressing to myocardial imaging, cardiac PET, and the multi-faceted discipline that is now an essential part of clinical cardiology (Table 8.1).

Along the way, UK-based researchers and clinicians have made significant contributions. Groups based in Aberdeen (cardiac PET), Northwick Park Hospital (technetium-based perfusion tracers), St Bartholomew's Hospital (first pass blood pool imaging), Hammersmith Hospital (cardiac PET), University College Hospitals

\footnotetext{
S.R. Underwood

Department of Nuclear Medicine, Imperial College London, Royal Brompton Hospital, Sydney St, London SW3 6NP, UK 
Table 8.1 Developing techniques in nuclear cardiology

\begin{tabular}{l|l}
\hline Decade & Clinical developments \\
\hline$\leq 1960 \mathrm{~s}$ & Experimental \\
\hline $1970 \mathrm{~s}$ & Blood pool imaging \\
\hline $1980 \mathrm{~s}$ & Thallium, diagnosis, cardiac cameras, pharmacological stress \\
\hline $1990 \mathrm{~s}$ & Technetium perfusion tracers, prognosis, attenuation correction, reconstruction techniques \\
\hline $2000 \mathrm{~s}$ & Hibernation, cost-effectiveness, solid state cameras, SPECT-CT, competing techniques \\
\hline $2010 \mathrm{~s}$ & Patient outcome, new tracers, cardiac PET-CT, inflammation and infection imaging \\
\hline
\end{tabular}

(ECG-gated SPECT, rubidium-82, solid state cameras), Manchester Royal Infirmary (rubidium-82) and Royal Brompton \& Harefield Hospitals (pharmacological stress, heart failure, cost-effectiveness) have all influenced the field internationally. The BNMS can be proud of the achievements of its members.

\subsection{Radionuclide Ventriculography}

In the late 1970s and early 1980s radionuclide ventriculography (RNV) was the main nuclear cardiology technique and it was used increasingly as an accurate and reproducible method of assessing left ventricular (LV) function. Although equilibrium imaging was most commonly used, first pass imaging had particular advantages for assessing right ventricular function and intra-cardiac shunting, as successfully used by the paediatric cardiologists at Guy's Hospital [1]. Parametric imaging provided simple methods of visualising regional function from the phase and amplitude images [2]. The Institute of Nuclear Medicine under the guidance of Peter Ell at the Middlesex Hospital demonstrated the value of such functional imaging in clinical practice (Fig. 8.1), and the phase image in particular continues to be of interest in assessing ventricular dysynchrony before resynchronisation pacing in patients with heart failure. This group also pioneered gated blood pool tomography [3] but with only two $100 \mathrm{~ms}$ frames per cardiac cycle it was not until image acquisition and processing techniques improved that it became a realistic technique as used today.

The simplicity and reproducibility of RNV meant that it was the technique of choice for serial assessments of LV function in patients having cardiotoxic chemotherapy or after heart transplantation but the increasing availability of echocardiography and its lack of ionising radiation led to it effectively replacing RNV. The availability of accurate methods of assessing LV function from gated myocardial SPECT led to a further decline, although RNV remains a valuable technique when echocardiography or magnetic resonance imaging (MRI) are not possible. 


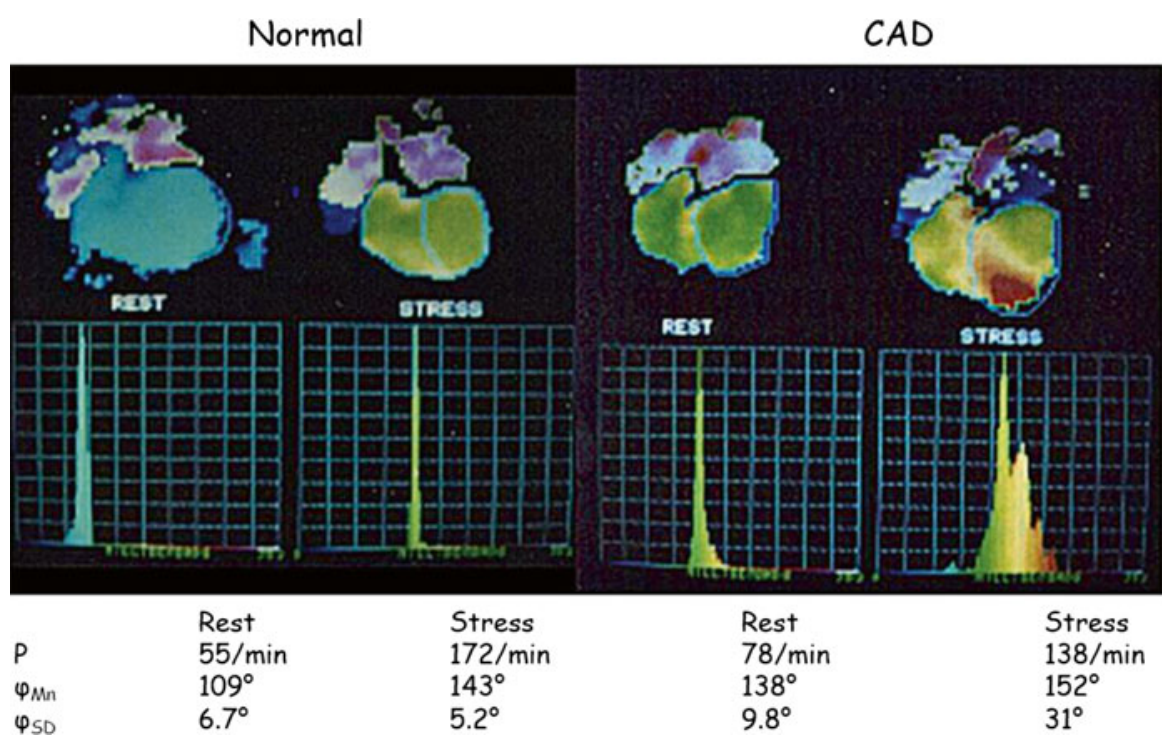

Fig. 8.1 The phase image and LV phase histograms from equilibrium radionuclide ventriculography acquired at rest and during maximal dynamic exercise in a patient without coronary disease (left $)$ and one with significant left anterior descending disease $(r i g h t)$. Mean phase $\left(\varphi_{\mathrm{Mn}}\right)$ increases with heart rate $(P)$ but the standard deviation of phase $\left(\varphi_{\mathrm{SD}}\right)$ broadens in the patient with LAD disease indicating delayed contraction in the relevant area. The standard deviation of the phase histogram is a sensitive method of detecting inducible ischaemia

\subsection{Myocardial Perfusion Scintigraphy}

As RNV was becoming less popular, so the combined assessment of myocardial viability and perfusion using thallium-201 and technetium-99m MIBI and tetrofosmin developed. Myocardial perfusion scintigraphy (MPS) is now the dominant nuclear cardiology technique that should be available to all cardiac services although appropriate expertise is not always available and there are still UK sites that rely on other techniques for coronary functional imaging. Planar MPS was effectively replaced by SPECT in the 1980s and it has developed from a diagnostic technique to a method of assessing prognosis and hence guiding clinical management and improving clinical outcome in patients with coronary artery disease (CAD). MPS SPECT has also become an alternative to FDG PET in assessing patients with ischaemic LV dysfunction and possible hibernating myocardium (Fig. 8.2) [4].

When the technetium-99m labelled perfusion tracers, MIBI and tetrofosmin were introduced in the 1990s many sites switched entirely to these despite some of their disadvantages [5]. Apart from commercial marketing, one driver for the change was the lower radiation burden of the technetium tracers. However, several recalculations 


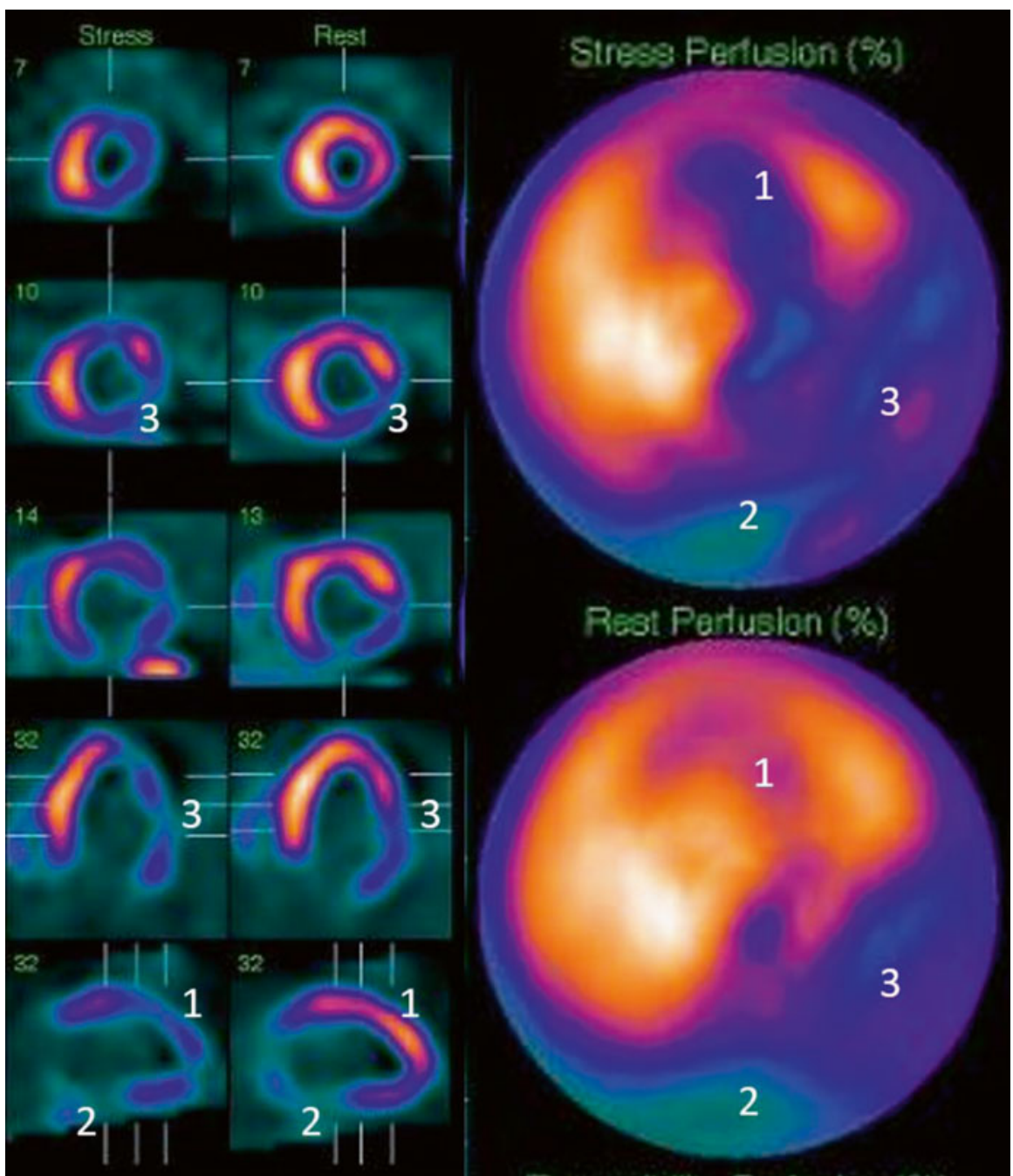

Fig. 8.2 Myocardial perfusion scintigraphy in an patient with ischaemic heart disease and heart failure. The antero-apical region (1) is almost fully viable but has inducible hypoperfusion. ECGgating showed it also to be akinetic without thickening and hence hibernating. There is also transmural infarction of the basal inferior wall (2) extending as partial thickness scarring of the infero-lateral region (3). LVEF was $30 \%$ but improved to $48 \%$ after revascularisation

have almost equalised the effective doses at 6,7 and $8 \mathrm{mSv}$ for $1000 \mathrm{MBq}$ of tetrofosmin, MIBI and $80 \mathrm{MBq}$ of thallium respectively [6]. With this new information and the superior uptake characteristics for the quantification of perfusion in absolute terms using dynamic SPECT, thallium MPS may yet see a resurgence. 


\subsection{Pharmacological stress}

One of the strengths of MPS is that it is not necessary for the patient to exercise maximally and pharmacological stress of myocardial perfusion became particularly prevalent in the UK in the 1980s and beyond, such that it is now used in the majority of studies instead of dynamic exercise. The coronary vasodilator dipyridamole was initially used following validation work by Gould in dogs and it is still the commonest pharmacological stressor in countries such as France, primarily because it is cheap. The Royal Brompton group was among the first to combine it with dynamic exercise in order to improve image quality and reduce side effects [7]. They later extended this to adenosine stress [8], which effectively replaced dipyridamole in the UK because of its shorter half-life and hence safety and practicality. They were also the first group in Europe to use the more specific A2a adenosine receptor agonist, regadenoson [9], which extended the options for stressing patients with obstructive airways disease and potentially also those with conducting tissue disease.

\subsection{NICE and the UK Societies}

As the NICE programme of clinical guidelines and technology appraisals grew in the 1990s it was apparent that the focus of healthcare providers was moving from evidence of effectiveness to cost-effectiveness to clinical outcomes. At this stage there were only computer-based estimates of cost effectiveness with no supporting clinical studies. However, in 1999 clinical cost-effectiveness studies from the UK [10] and USA [11] provided strong support for MPS at a time when there was no similar evidence to support alternatives. The data were considered by NICE and formed part of the evidence for the first technology appraisal of an imaging technique in cardiology [12]. More recently, the Cambridge group led what is still the only prospective randomised study of non-invasive imaging compared with invasive angiography and confirmed the cost-effectiveness of MPS compared with echocardiography and MRI [13].

In assisting the technology appraisal of MPS, the BNMS, BNCS and other professional bodies collaborated to review the evidence for MPS in clinical practice and the resulting publication became the most quoted EJNM publication in 2008 [14]. Since then, an alphabet cocktail of studies (BARI, COURAGE, DEFER, ERASE, FAME, GRACE, INSPIRE, etc.) has shown, among other things, that ischaemia-guided intervention in patients with CAD leads to better clinical outcomes. It should now be unusual for patients with stable disease to undergo revascularisation procedures without some form of functional assessment. The challenge for the future will be to show the advantages of doing this by nuclear cardiology in preference to alternative techniques that in some centres have replaced nuclear cardiology because of more ready access to expertise and equipment. 


\subsection{The Future}

Whether nuclear cardiology will move towards PET from SPECT is unclear. FDG PET is already very valuable for the assessment of myocardial inflammation and infection, such as in sarcoidosis and infected devices (Fig. 8.3).

For perfusion imaging the future is less clear. UK groups have been at the forefront of using rubidium- 82 PET, the only perfusion technique that is feasible without an on-site cyclotron, but PET may not gain wide acceptance until more cost-effective techniques become available, possibly such as flurpiridaz, a fluorine18 labelled perfusion tracer currently in phase 3 trials. In addition, the availability of high resolution and sensitive solid state cameras with the ability to quantify perfusion may challenge PET (Fig. 8.4) [15, 16].

There is the prospect of moving nuclear cardiology into the world of electrophysiology interventions, such as ablation of atrial fibrillation and ventricular arrhythmias. Pilot studies between University College and Royal Brompton Hospitals and have shown that mIBG combined with a solid state camera can localise ganglionated plexi of the sympathetic nervous system that are related to the control of arrhythmia and are potential targets for intervention (Fig. 8.5).

Reports of the demise of nuclear cardiology have therefore been exaggerated. Its future seems assured provided that we continue our proud history within the BNMS of contributing to research, education and clinical application in the field.
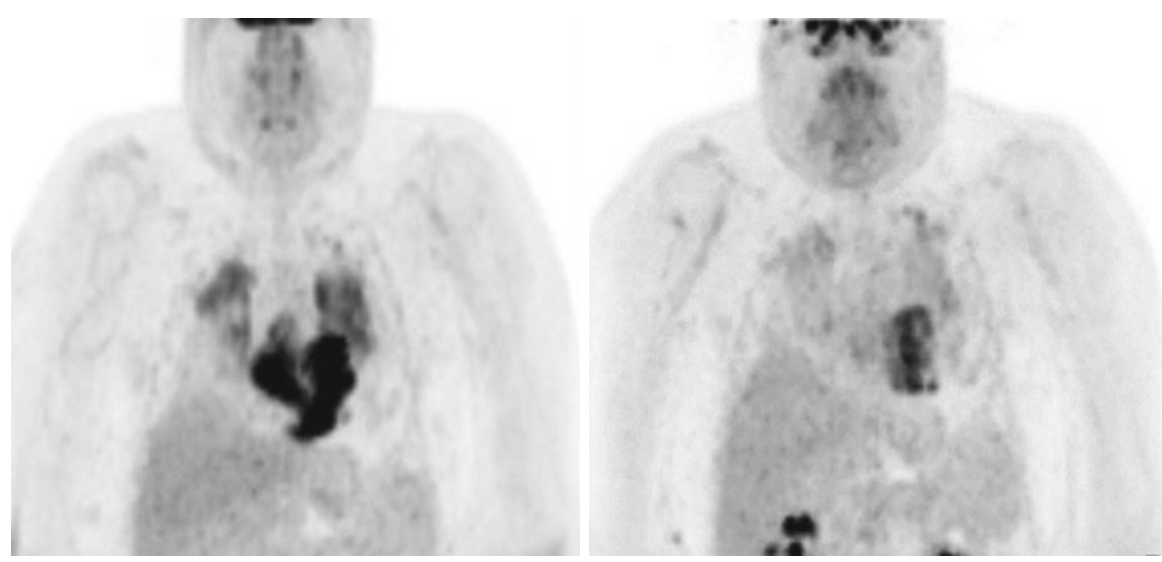

Fig. 8.3 FDG PET in the coronal plane in a patient with cardiac sarcoidosis before (left) and 10 months after steroid therapy ( right). The images are acquired in the fasting state to suppress normal myocardial glucose metabolism. There is intense abnormal activity in the heart and hilar regions that is partially suppressed after treatment (Courtesy Dr K Wechalekar, Royal Brompton Hospital) 


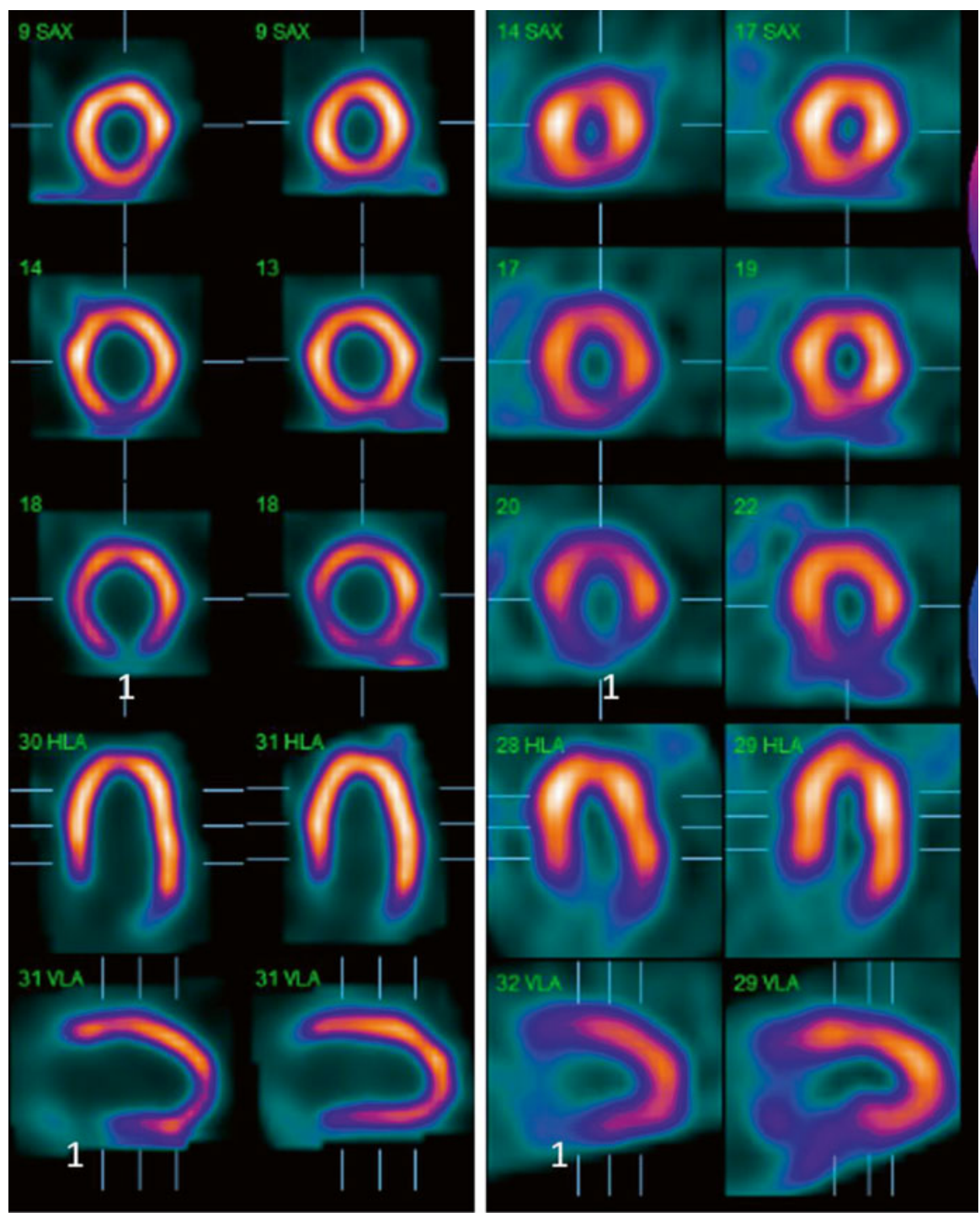

Fig. 8.4 Myocardial perfusion scintigraphy in an patient with known coronary disease, acquired using a solid state gamma camera in 4 min (left) and a conventional camera in 12 min (right). In each case stress tomograms are on the left and rest on the right. Both studies show an inducible perfusion abnormality of the basal inferior wall (1) but the superior spatial and contrast resolution of the solid state camera is obvious 


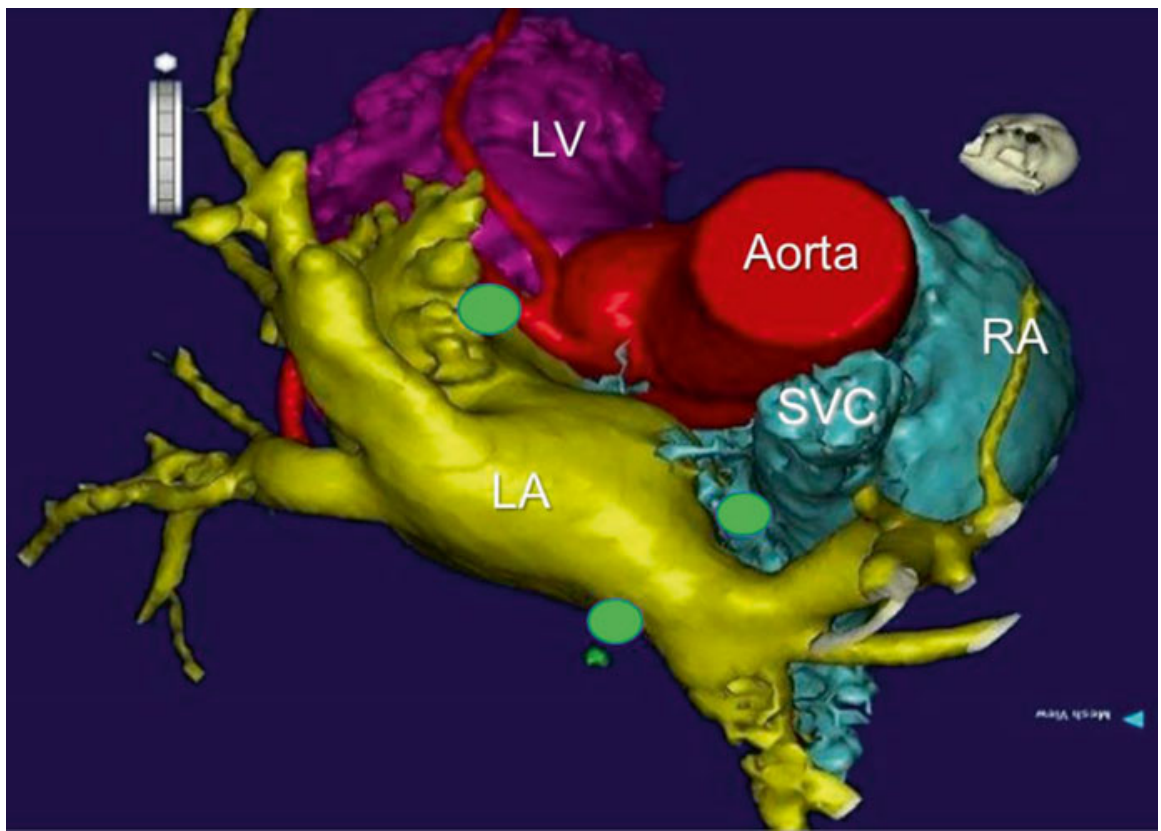

Fig. 8.5 Segmented CT scan with the sites of ganglionated plexi (GPs) superimposed (green ovals) imaged using iodine- $123 \mathrm{mIBG}$ and a solid state gamma camera. The fused images can be imported into the electrophysiology laboratory system to aid localisation of the GPs and ablation (Courtesy Dr Sabine Ernst, Royal Brompton Hospital). $L A$ left atrium, $L V$ left ventricle, $R A$ right atrium, $S V C$ superior vena cava

Open Access This chapter is distributed under the terms of the Creative Commons AttributionNoncommercial 2.5 License (http://creativecommons.org/licenses/by-nc/2.5/) which permits any noncommercial use, distribution, and reproduction in any medium, provided the original author(s) and source are credited.

The images or other third party material in this chapter are included in the work's Creative Commons license, unless indicated otherwise in the credit line; if such material is not included in the work's Creative Commons license and the respective action is not permitted by statutory regulation, users will need to obtain permission from the license holder to duplicate, adapt or reproduce the material.

\section{References}

1. Baker EJ, Ellam SV, Lorber A, Jones OD, Tynan MJ, Maisey MN. Superiority of radionuclide over oximetric measurement of left to right shunts. Br Heart J. 1985;53:535-40.

2. Underwood SR, Walton S, Laming PJ, Ell PJ, Emanuel RW, Swanton RH. Quantitative phase analysis in the assessment of coronary artery disease. Br Heart J. 1989;61:14-22.

3. Underwood SR, Walton S, Ell PJ, Jarritt PH, Emanuel RW, Swanton RH. Gated blood pool emission tomography: a new technique for the investigation of cardiac structure and function. Eur J Nucl Med. 1985;10:332-7. 
4. Gunning MG, Anagnostopoulos C, Knight CJ, Pepper JR, Burman ED, Davies G, Fox KM, Pennell DJ, Ell PJ, Underwood SR. Comparison of Tl-201, technetium-99m tetrofosmin and dobutamine magnetic resonance imaging in identifying hibernating myocardium. Circulation. 1998;98:1869-74.

5. Kapur A, Latus KA, Davies G, Dhawan R, Eastick S, Jarritt PH, Roussakis G, Young M, Anagnostopoulos C, Bomanji J, Costa D, Pennell DJ, Prvulovich EM, Ell PJ, Underwood SR. A comparison of three radionuclide myocardial perfusion tracers in clinical practice: the ROBUST study. Eur J Nucl Med Mol Imaging. 2002;29:1608-16.

6. Andersson M, Johansson L, Minarik D, Leide-Svegborn S, Mattsson S. Effective dose to adult patients from 338 radiopharmaceuticals estimated using ICRP biokinetic data, ICRP/ICRU computational reference phantoms and ICRP 2007 tissue weighting factors. Eur J Nucl Med Mol Imaging Phys. 2014;1:9.

7. Pennell DJ, Mavrogeni S, Anagnostopoulos C, Ell PJ, Underwood SR. Thallium myocardial perfusion tomography using intravenous dipyridamole combined with maximal dynamic exercise. Nucl Med Commun. 1993;14:939-45.

8. Pennell DJ, Mavrogeni S, Forbat SM, Karwatowski SP, Underwood SR. Adenosine combined with dynamic exercise for myocardial perfusion imaging. J Am Coll Cardiol. 1995;25: 1300-9.

9. Brinkert M, Reyes E, Walker S, Latus KA, Maenhout AF, Mizumoto R, Nkomo Q, Standbridge $\mathrm{K}$, Wechalekar K, Underwood SR. Regadenoson in Europe: first-year experience of regadenoson stress combined with submaximal exercise in patients undergoing myocardial perfusion scintigraphy. Eur J Nucl Med Mol Imaging. 2014;41:511-21.

10. Underwood SR, Godman B, Salyani S, Ogle J, Ell PJ. Economics of myocardial perfusion imaging in Europe: the EMPIRE study. Eur Heart J. 1999;20:157-66.

11. Shaw LJ, Hachamovitch R, Berman DS, Marwick TH, Lauer MS, Heller GV, Iskandrian AE, Kesler KL, Travin MI, Lewin HC, Hendel RC, Borges-Neto S, Miller DD. The economic consequences of available diagnostic and prognostic strategies for the evaluation of stable angina patients: an observational assessment of the value of precatheterisation ischaemia. J Am Coll Cardiol. 1999;33:661-9.

12. NICE technology appraisal guidance [TA73]. Myocardial perfusion scintigraphy for the diagnosis and management of angina and myocardial infarction. https://www.nice.org.uk/guidance/ ta73. Accessed 8 Nov 2015.

13. Thom H, West NEJ, Hughes V, Dyer M, Buxton M, Sharples LD, Jackson CH, Crean AM, Armstrong J, Buxton M, Caine N, Coulden R, Crean A, Dyer M, Gillham M, Goddard H, Goldsmith K, Hughes V, Lee E, Patel R, Schofield P, Sharples L, Sonnex E, Stone D, Treacy C. Cost-effectiveness of initial stress cardiovascular MR, stress SPECT or stress echocardiography as a gate-keeper test, compared with upfront invasive coronary angiography in the investigation and management of patients with stable chest pain: mid-term outcomes from the CECaT randomised controlled trial. BMJ Open. 2014;4:e003419.

14. Underwood SR, Anagnostopoulos C, Cerqueria MD, Ell PJ, Flint E, Harbinson MT, Kelion A, Al-Mohammad A, Prvulovich EM, Shaw LJ, Tweddel AC. Myocardial perfusion scintigraphy: the evidence. Eur J Nucl Med. 2004;31:261-91.

15. Ben-Haim S, Murthy VL, Breault C, Allie R, Sitek A, Roth N, Fantony J, Moore SC, Park M-A, Kijewski M, Haroon A, Slomka P, Erlandsson K, Bavvour R, Zilberstien Y, Bomanji J, Carli MFD. Quantification of myocardial perfusion reserve using dynamic SPECT imaging in humans: a feasibility study. J Nucl Med. 2013;54:873-9.

16. Chowdhury FU, Vaidyanathan S, Bould M, Marsh J, Trickett C, Dodds K, Clark TPR, Sapsford RJ, Dickinson CJ, Patel CN, Thorley PJ. Rapid-acquisition myocardial perfusion scintigraphy (MPS) on a novel gamma camera using multipinhole collimation and miniaturized cadmiumzinc-telluride (CZT) detectors: prognostic value and diagnostic accuracy in a 'real-world' nuclear cardiology service. Eur Heart J Cardiovasc Imaging. 2014;15:275-83. 


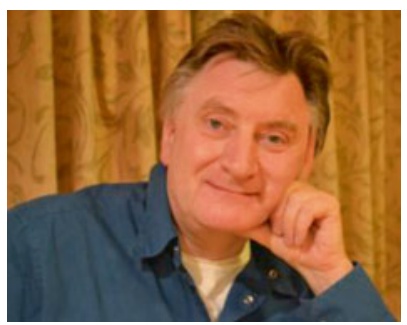

S. Richard Underwood Richard Underwood gained a first class honours degree in chemistry at Merton College, University of Oxford, which included a period working in George Radda's laboratory using NMR and ESR in biological systems. He went on to study medicine, graduating in 1977. After general medical training he specialised in cardiac medicine learning both noninvasive and invasive techniques, and for the last 20 years he has practised noninvasive cardiac imaging, with major clinical and research interests in nuclear cardiology, magnetic resonance and in cardiovascular X-ray computed tomography.

Since 1985, Professor Underwood has worked at Royal Brompton Hospital, London and its academic wing, the National Heart and Lung Institute, Imperial College School of Medicine. He has been closely involved in the development of magnetic resonance techniques for the investigation of the cardiovascular system, and has contributed substantially to its progression from research technique to every-day clinical tool. His current research interests include the assessment of myocardial perfusion using pharmacological stress, the characterisation of hibernating myocardium, and the cost-effectiveness of cardiac imaging techniques. He has published and lectured widely and has directed or co-directed important training courses on nuclear cardiology at national and international level.

$\mathrm{He}$ is professor of cardiac imaging at the National Heart and Lung Institute, Imperial College London, and honorary consultant at Royal Brompton \& Harefield Hospitals. External commitments include past-chairman of the ESC working group on nuclear cardiology and magnetic resonance, past-chair of the British Nuclear Cardiology Society and the International Congress of Nuclear Cardiology, and current member of the European Council on Nuclear Cardiology.

Non-medical interests include aviation, skiing and gastronomy.

S Richard Underwood, DM, FRCP, FRCR

Professor of Cardiac Imaging, Imperial College London 